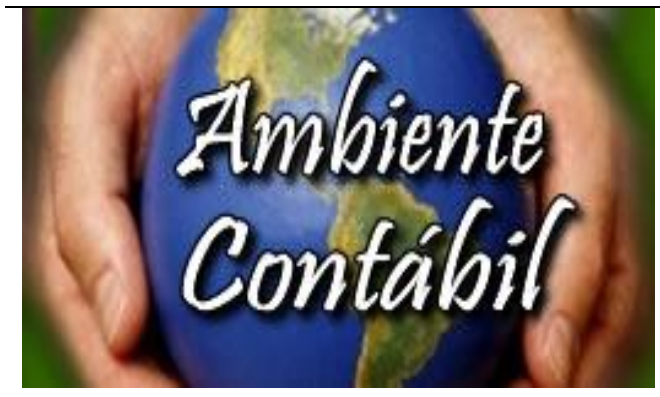

REVISTA AMBIENTE CONTÁBIL

Universidade Federal do Rio Grande do Norte

ISSN 2176-9036

Vol. 9. n. 2, jul./dez. 2017

Sítios: http://www.periodicos.ufrn.br/ambiente

http://ccsa.ufrn.br/ojs/index.php?journal=contabil

http:/www.atena.org.br/revista/ojs-2.2.3-06/index.php/Ambiente

Artigo recebido em: 04.09.2016. Revisado por pares em:

19.04.2017. Reformulado em: 24.05.2017. Avaliado pelo sistema double blind review.

\title{
ANÁLISE ECONÔMICO-FINANCEIRA MEDIANTE GERAÇÃO E COMERCIALIZAÇÃO DE CRÉDITOS DE CARBONO
}

\section{ANALYSIS ECONOMIC AND FINANCIAL BY GENERATION AND CARBON CREDITS TRADING}

\section{ANÁLISIS ECONÓMICO Y FINANCIERO POR GENERACIÓN Y COMERCIAR CRÉDITOS DE CARBONO \\ IRANI S/A}

Autores

Renata Lúcia Basso

Especialista em Auditoria e Controladoria pelo Centro Universitário Franciscano UNIFRA. Trabalha na Empresa Vision Consultoria e Auditoria. Endereço: Rua Silva Jardim, nº1175, CEP: 97.010-491, $2^{\circ}$ andar - Santa Maria, RS, Brasil. Telefone: (55) 9174-4820.

Identificadores (ID):

Lattes: http://lattes.cnpq.br/6489783451775233

E-mail: renatalucia91@hotmail.com

Daniele Dias de Oliveira Bertagnolli

Mestre em Ciências Contábeis pela Universidade do Vale do Rio dos Sinos - UNISINOS.

Professora e coordenadora do Curso de Ciências Contábeis do Centro Universitário

Franciscano - UNIFRA. Endereço: Rua Silva Jardim, nº 1175, CEP: 97.010-491, $2^{\circ}$ andar Santa Maria, RS, Brasil. Telefone: (55) 3025-1202.

Identificadores (ID):

Lattes: http://lattes.cnpq.br/1474071536717845

E-mail: daniele@unifra.br

Lucas Almeida dos Santos

Doutorando em Administração pela Universidade Federal de Santa Maria - UFSM. Professor do ensino superior no Centro Universitário Franciscano - UNIFRA. Endereço: Av. Nossa Senhora Medianeira, $\mathrm{n}^{\circ}$ 2027, Apto. 05, CEP: 97060-002 - Santa Maria, RS, Brasil. Telefone:

(55) 9937-6402

Identificadores (ID):

Lattes: http://lattes.cnpq.br/1175673329333533

E-mail: luksanttos@gmail.com 


\title{
RESUMO
}

Os créditos de carbono podem ser comercializados criando receitas extras para as empresas que investem na sustentabilidade. Dessa forma, o estudo tem como objetivo geral analisar como a participação em projetos de MDL e geração de créditos de carbono auxiliam na situação econômico-financeira da organização. A pesquisa apresenta-se como um estudo de caso de natureza aplicada, descritiva, exploratória, documental, sendo de acordo com os procedimentos quali-quantitativa. Durante a pesquisa foi possível conhecer as características da empresa, os processos operacionais necessários para geração dos créditos de carbono e a verificação da situação econômico-financeira no período de 1997 a 2011. A partir desta análise, constata-se que a participação da empresa em projetos de MDL para a geração de créditos de carbono influencia positivamente a situação econômico-financeira da empresa, visto que se não fosse considerada a receita extra dos créditos de carbono, os índices apresentariam um desempenho mais baixo. Portanto, foi possível notar que os créditos de carbono, podem ser um elemento chave para o crescimento e solidez das empresas, já que a procura pela redução da poluição e a busca por processos ambientalmente limpos é indispensável para sua garantia e permanência no mercado.

Palavras-chave: Protocolo de Quioto. MDL. Créditos de Carbono. Análise econômicofinanceira.

\begin{abstract}
Carbon credits can be traded creating extra revenue for companies that invest in sustainability. Thus, the study has the general objective to analyze how participation in CDM projects and carbon credit generation assist in the economic and financial situation of the organization. The research is presented as a case study nature applied, descriptive, exploratory, document, and according to the qualitative and quantitative procedures. During the research it was possible to know the characteristics of the company, operating processes necessary for the generation of carbon credits and verification of the economic and financial situation in the period from 1997 to 2011. From this analysis, it appears that the company's participation in CDM projects to generate carbon credits positively influences the economic and financial situation of the company, since it was not considered the extra revenue from carbon credits, the indices present a lower performance. So it was possible to note that carbon credits can be a key element for the growth and strength of the companies, as the demand for reduction of pollution and the search for environmentally clean process is essential for its security and permanence in the market.
\end{abstract}

Keywords: Kyoto Protocol. CDM. Carbon Credits. Economic and financial analysis.

\section{RESUMEN}

Los créditos de carbono se pueden negociar la creación de ingresos adicionales para las empresas que invierten en sostenibilidad. Por lo tanto, el estudio tiene como objetivo general analizar cómo la participación en proyectos MDL y la generación de créditos de carbono ayudar en la situación económica y financiera de la organización. La investigación se presenta como un estudio de caso la naturaleza aplicada, descriptiva, exploratoria, documento, y de acuerdo con los procedimientos cualitativos y cuantitativos. Durante la investigación fue posible conocer las características de la empresa, los procesos necesarios de funcionamiento para la generación de créditos de carbono y la verificación de la situación económica y financiera en el período de 1997 a 2011. A partir de este análisis, se observa que la

Revista Ambiente Contábil - ISSN 2176-9036 - UFRN - Natal-RN. v. 9. n. 2, p. 296 - 314, jul./dez. 2017. 
participación de la compañía en proyectos MDL para generar créditos de carbono influye positivamente en la situación económica y financiera de la empresa, ya que no se consideró el ingreso adicional de créditos de carbono, los índices presentan un menor rendimiento. Por lo tanto, era posible observar que los créditos de carbono puede ser un elemento clave para el crecimiento y la fuerza de las empresas, ya que la demanda de reducción de la contaminación y la búsqueda de procesos ambientalmente limpio es esencial para su seguridad y permanencia en el mercado.

Palabras clave: Protocolo de Kyoto. MDL. Créditos de carbono. Análisis económico y financiero.

\section{INTRODUÇÃO}

A degradação do meio ambiente atingiu níveis elevados devido às ações humanas, que tornaram obrigatórias ações preventivas e de recuperação ambiental. A partir das consequências climáticas geradas pelo acelerado desenvolvimento econômico passa a existir a necessidade de todos os setores da sociedade auxiliarem na preservação do meio ambiente. A existência de ações globais tem feito com que muitas organizações (re)pensem seus meios de produção e reflitam acerca da preservação do meio ambiente, o que outrora era visto como um tabu. Nesse sentido, a partir da década de 80, muitas tem sido as discussões em todas as áreas de conhecimento, estando a contabilidade inserida neste escopo.

Assim sendo, emerge a possibilidade de empresas brasileiras participarem ativamente na preservação dos recursos ambientais por meio de projetos de Mecanismo de Desenvolvimento Limpo (MDL) implantados pelo Protocolo de Quioto, o qual trouxe para o Brasil a oportunidade de geração dos créditos de carbono, a partir de investimentos em inovações tecnológicas para que as companhias reduzam a emissão dos gases poluentes de seus processos produtivos, aliando desenvolvimento e sustentabilidade.

Conforme Freire et al. (2015), devido às questões legais e sociais, empresas poluidoras passaram a usar novas estratégias a fim de adquirir diferencial competitivo perante suas concorrentes, desta forma, a redução dos níveis de poluição e a entrada no mercado de créditos de carbono tornaram-se mais um importante caminho para as organizações maximizarem seus resultados. Uma opção para empresas brasileiras é a venda de certificados de créditos de carbono por meio da implementação de projetos com o intuito de reduzir a emissão de gases poluentes.

Em se tratando da ciência contábil, assim como as demais, esta encontra-se engajada com atividades que buscam a sustentabilidade do planeta, pois torna-se imprescindível a participação desta como provedora de informações financeiras, tratando o crédito de carbono como uma fonte de receita para a empresa, além da melhoria para a qualidade de vida dos seres humanos. Para tanto, o impacto que a geração de créditos de carbono resulta para a empresa, não está apenas no econômico-financeiro, mas sim na sobrevivência das organizações no atual cenário de atuação.

Diante do exposto, tendo em vista os novos desafios referentes ao desenvolvimento sustentável, atrelado ao desenvolvimento das empresas no âmbito organizacional, o presente estudo tem como problemática a seguinte questão: como a participação da empresa em projetos de MDL e a venda de créditos de carbono auxiliam na situação econômicofinanceira da organização? Assim, o estudo tem como objetivo geral analisar como a participação em projetos de Mecanismo de Desenvolvimento Limpo (MDL) e geração de créditos de carbono auxiliam na situação econômico-financeira da organização.

Visando atender a problemática estabelecida, esta pesquisa foi desenvolvida em uma empresa de grande porte, com atuação nacional e internacional atuando no segmento de celulose, ou seja, na fabricação de diversos tipos de papéis e seus derivados, tendo como

Revista Ambiente Contábil - ISSN 2176-9036 - UFRN - Natal-RN. v. 9. n. 2, p. 296 - 314, jul./dez. 2017. 
objetivo geral analisar como a participação da empresa em projetos de MDL e a venda de créditos de carbono auxiliam na situação econômico-financeira da organização. Para tanto, tornou-se necessário, também, realizar um estudo com o intuito de conhecer as características da empresa pesquisada, os procedimentos operacionais e a análise de índices financeiros no que tange a influência dos créditos de carbono na situação da empresa.

Ademais, a abordagem que este estudo apresenta justifica-se pela importância que demonstra para a área empresarial e social à medida que buscou mostrar como a utilização de um processo produtivo sustentável, por meio da geração de créditos de carbono, pode trazer resultados positivos às instituições e à sociedade dado a situação econômico-financeira das empresas durante o período de geração e posterior comercialização dos créditos. Nesse sentido, tem-se como contribuição do estudo a apresentação dos resultados que pode auxiliar as corporações a perceberem uma oportunidade de sucesso em seu negócio, uma forma de melhorar a competitividade aliando desenvolvimento e sustentabilidade por meio de investimentos na geração e comercialização de créditos de carbono.

A contribuição dos créditos de carbono também foi abordada em estudos anteriores, como no de Valdetaro et al. (2011), que avaliaram a contribuição dos créditos de carbono na viabilidade econômica nos contratos de fomento florestal da região do extremo sul da Bahia, os resultados da pesquisa mostraram que a comercialização dos créditos de carbono pode aumentar consideravelmente a viabilidade financeira do contrato de fomento e que o comércio de créditos de carbono aumentará os ganhos dos produtores fomentados.

\section{REFERENCIAL TEÓRICO}

A seguir serão abordados os principais assuntos relevantes a temática, construído a partir das ideias dos especialistas da área, servindo de base para a construção dos resultados e alcance do objetivo estipulado.

\subsection{AQUECIMENTO GLOBAL E PROTOCOLO DE QUIOTO}

A problemática do aquecimento global está relacionada à quantidade em excesso dos gases de efeito estufa existentes em nossa atmosfera. De acordo com Limiro (2011), estudos do Painel Intergovernamental sobre Mudança do Clima (IPCC), relacionam o aumento na temperatura global com as atividades desenvolvidas pelos seres humanos, principalmente o uso de combustíveis fósseis, cuja utilização se iniciou na Revolução Industrial. Assim, o problema da poluição ambiental e do aquecimento global vem se agravando por meio da intervenção humana no planeta, principalmente pela queima de carvão mineral, de petróleo e de gás natural como fontes de energia para atividades industriais.

Com isso, mediante a preocupação com a interferência do homem no meio ambiente, que em 1997 na cidade de Quioto no Japão foi assinado o Protocolo de Quioto, com o objetivo de fazer com que os países industrializados reduzissem as emissões dos gases de efeito estufa (GEEs). Segundo Seiffert (2009), apenas os países desenvolvidos são obrigados a reduzir suas emissões, uma vez que, os países em desenvolvimento poderiam participar do acordo voluntariamente.

Dessa forma, no intuito de que os países desenvolvidos pudessem atingir suas metas de redução ao menor custo possível, foram implementados três mecanismos de flexibilização: o Comércio de Emissões, a Implementação Conjunta e o Mecanismo de Desenvolvimento Limpo (MDL). Conforme Gazoni (2007), os mecanismos de flexibilização têm o propósito de incentivar os países emergentes a alcançar um modelo adequado de desenvolvimento sustentado. 
Assim, o MDL tornou-se o único mecanismo de flexibilização que permite a participação das nações em desenvolvimento, como no caso do Brasil, uma vez que foi por meio do MDL que surgiram os créditos de carbono. Nesta concepção, Barbieri e Ribeiro (2007), apontam que o MDL envolve a implantação de projetos para diminuir e eliminar GEEs nos países em desenvolvimento, os quais poderão ser financiados pelos desenvolvidos em troca de créditos para serem abatidos dos seus compromissos de redução de emissões impostos pelo Protocolo. Deste modo, as nações desenvolvidas que extrapolam o limite de emissão podem comprar os créditos de carbono daquelas que estão em desenvolvimento, para equilibrar suas metas de emissão de GEEs.

\subsection{PROJETOS DE MECANISMO DE DESENVOLVIMENTO LIMPO (MDL)}

O Mecanismo de Desenvolvimento Limpo (MDL), na concepção de Delgado e Altheman (2007), tem por objetivo alcançar e renovar meios sustentáveis de produção em países em desenvolvimento a partir da implantação de tecnologias mais limpas. Também é um mecanismo que facilita o cumprimento das metas de redução das emissões de GEEs dos países desenvolvidos (TEIXEIRA et al., 2010).

Nesse sentido, o parágrafo $5^{\circ}$, do artigo $12^{\circ}$, do Protocolo de Quioto relaciona os requisitos essenciais para que projetos de MDL resultem na obtenção de certificados de Reduções Certificadas de Emissões (RCEs). São eles: a participação voluntária aprovada por cada parte envolvida; benefícios reais, mensuráveis e de longo prazo relacionados com a mudança do clima; reduções de emissões que sejam adicionais as que ocorreriam naturalmente (COELHO et al., 2008; PROTOLO DE QUIOTO, 2012).

Frondizi (2009) aponta que o mecanismo de desenvolvimento limpo encontra-se baseado no desenvolvimento de projetos que tem como responsável a iniciativa privada. As atividades de projetos de MDL nos países em desenvolvimento devem apresentar benefícios reais, mensuráveis e de longo prazo. Ademais, estes projetos também devem estar relacionados à redução nas emissões GEEs ou pelo menos influenciar a incidência de $\mathrm{CO} 2$.

Numa visão mais ampla, no que tange a tramitação de um projeto MDL obedece a uma lógica semelhante à Certificação de Sistemas de Gestão, conforme modelo da ISO. Segundo os autores Lombardi (2008) e Seiffert (2009), estes partilham da mesma ideia ao afirmar que neste processo aparecem diferentes agentes importantes: a Autoridade Nacional Designada (AND), Entidade Operacional Designada (EOD) e o Comitê Executivo do MDL (CEMDL). Todos asseguram a credibilidade do processo de certificação dos Créditos de Carbono.

No Quadro 1 é possível verificar as etapas que as organizações necessitam cumprir para que possam desenvolver projetos de MDL.

Quadro 1 - Etapas de Desenvolvimento do Projeto de MDL

\begin{tabular}{|l|l|}
\hline 1 & Estudo de viabilidade do projeto \\
\hline 2 & Elaboração do documento de concepção de projeto (DCP) \\
\hline 3 & Validação por uma Entidade Operacional Designada (EOD) \\
\hline 4 & Aprovação pela Autoridade Nacional Designada (AND) \\
\hline 5 & Submissão ao Conselho Executivo do (MDL) para registro do projeto \\
\hline 6 & Monitoramento da Emissão de Redução do GEE \\
\hline 7 & Verificação do(s) relatório(s) de monitoramento por uma EOD \\
\hline 8 & Emissão do RCE pelo Conselho Executivo do MDL \\
\hline
\end{tabular}

Fonte: Adaptado de Cruz e Paulino (2013).

Revista Ambiente Contábil - ISSN 2176-9036 - UFRN - Natal-RN. v. 9. n. 2, p. 296 - 314, jul./dez. 2017. 
Conforme exposto no Quadro 1, percebe-se que desde o início das atividades de um projeto MDL, a empresa pode efetuar seu registro no banco de projetos, o que evidencia a possibilidade de operações de financiamento de projetos. Assim de acordo com Conselho Empresarial Brasileiro para o Desenvolvimento Sustentável - CEBDS (2009), em estudo realizado, aponta que o projeto visa uma iniciativa maior que apenas evitar as mudanças climáticas e promover o desenvolvimento sustentável. Um projeto MDL deve também, além de proporcionar benefícios ao meio ambiente, proporcionar melhorias em termos de qualidade de vida da sociedade, como gerar empregos, por exemplo.

De acordo com Giovanini, Corsato e Monassa (2010), os autores concluíram em seu estudo acerca dos créditos de carbono no Brasil que embora o potencial ecológico contido no país permita desenvolver todas as modalidades de projetos MDL, o que se percebe é uma grande concentração de projetos de redução de emissão e emissões evitadas com base na geração de energia para os processos industriais. Falta o fomento a projetos de regaste de carbono, que apesar de não possuírem procedimentos de mensuração tão simplificados e claros como os das outras modalidades, beneficiam as florestas e outros ecossistemas mais diretamente.

Portanto, percebe-se que por meio do MDL é possível criar projetos de redução de emissão dos gases de efeito estufa, uma vez que essas atividades irão gerar os créditos de carbono. Assim, os projetos podem ser implantados em empresas e podem ser ligados à florestamentos e reflorestamentos, uso de energias alternativas, como a implantação de aterros controlados ou sanitários, uso de biocombustíveis, geração de energia a partir da biomassa, tratamento de efluentes, entre outros.

\subsection{MERCADO DOS CRÉDITOS DE CARBONO}

Como decorrência da política ambiental das empresas e o Protocolo de Quioto, observam-se a figura dos créditos de carbono. Acerca desta temática, Ribeiro (2005), aponta que os créditos de carbono surgiram nos países como meio de inibir a produção de poluentes. A legislação local estabeleceu níveis máximos de emissões de certos gases e aqueles que conseguissem manter volume de emissões abaixo do estabelecido tinha direito a títulos de créditos equivalentes à porção reduzida, os quais podiam ser vendidos àqueles que não tiveram o mesmo sucesso, e que não deveriam infringir as regras (BEN; TONELLO, 2007).

Diante deste contexto, ainda de acordo com Ben e Tonello (2007), as empresas que realizaram investimentos para melhorar a qualidade de seus processos operacionais teriam uma recompensa e, por outro lado, aqueles que não o fizeram, ou não fizeram em montante suficiente teriam que pagar pela poluição produzida. Com o advento do Protocolo de Quioto, esse mecanismo foi aperfeiçoado e adotado.

Assim sendo, o mercado de Créditos de Carbono teve como base principal o Protocolo de Quioto (SILVA; MACEDO, 2012), sendo que a partir deste, muitos movimentos foram iniciados para que efetivamente acontecesse um mercado relacionado às emissões de GEEs. Com isso, no ano 2000 foi lançado o Fundo Protótipo de Carbono, que era uma parceria entre dezessete empresas e seis governos gerenciados pelo Banco Mundial. A proposta deste fundo era de congregar, de um lado o dinheiro dos participantes e, de outro, projetos de MDL (LOMBARDI, 2008; INSTITUTO BRASIL CARBONO, 2012).

Dessa forma, iniciou-se um mercado de carbono efetivo por meio de uma commoditie comercializável para as reduções de emissões de GEEs, isto sendo possível pela determinação de padrões comuns em um mercado definido (SILVA; MACEDO, 2012). O sistema, de acordo com o Ministério da Ciência e Tecnologia - MCT (2012), envolvia a padronização e criação de um sistema de comércio que poderia ser utilizado para facilitar estes negócios, uma

Revista Ambiente Contábil - ISSN 2176-9036 - UFRN - Natal-RN. v. 9. n. 2, p. 296 - 314, jul./dez. 2017. 
vez que para esse caso, alguns aspectos necessitavam análise para a implementação de um mercado de carbono.

Ainda, de acordo com o MCT (2012), o conceito de crédito de carbono fundamentouse em vários artigos da Convenção Sobre Mudança do Clima que entrou em vigor em 1994. Nesta convenção, implementou-se um sistema econômico internacional favorável e aberto trazendo desenvolvimento econômico sustentável para todas as partes, o que permite que os países em desenvolvimento verifiquem seu potencial nas ações para redução das mudanças climáticas. Por outro lado, isso possibilita que países desenvolvidos implementem acordos multilaterais para prover recursos financeiros a países em desenvolvimento.

Em outras palavras Khalili (2003), aponta de forma ampla que os créditos de carbono são certificados que autorizam o direito de poluir. Para o autor, as agências de proteção ambiental reguladoras emitem certificados autorizando emissões de toneladas de dióxido de enxofre, monóxido de carbono e outros gases poluentes. Inicialmente, selecionam-se indústrias que mais poluem no País e a partir daí são estabelecidas metas para a redução de suas emissões.

Neste caso, as organizações recebem bônus negociáveis na proporção de suas responsabilidades, uma vez que cada bônus, cotado em US\$, equivale a uma tonelada de poluentes. Quem não cumpre as metas de redução progressiva estabelecidas por lei, tem que comprar certificados das empresas mais bem-sucedidas. $O$ sistema tem a vantagem de permitir que cada empresa estabeleça seu próprio ritmo de adequação às leis ambientais (BEN; TONELLO, 2007).

Com isso, o mercado de crédito de carbono se torna promissor para as empresas envolvidas com sua produção e venda. Neste sentido Robles Júnior e Bonelli (2006), elucidam que as empresas geradoras de créditos de carbono, ao venderem esses créditos, podem considerar o valor da venda como redutores do custo de produção, aumentando suas receitas e melhorando sua situação econômico-financeira. Por outro lado, o Mercado de Carbono deverá ser considerado um investimento natural de um governo, tonando-se um mercado voluntário para todos. Porém, em momentos de crise, quando houver necessidade de cortes financeiros, acredita que esse será o primeiro setor a ser sacrificado.

Como forma de comercialização, a BM\&FBOVESPA (Bolsa de Valores, Mercadorias e Futuros) elaborou um sistema eletrônico de leilões para intermediar a negociação do crédito de carbono no mercado à vista. A divulgação das regras de negociação e credenciamento dos participantes de cada leilão é realizada pela Bolsa por meio de editais que são publicados no site da BM\&FBOVESPA antes da data de realização de cada leilão (BM\&FBOVESPA, 2016).

No que tange a contabilização dos créditos de carbono, Uhlmann et al. (2012), sugerem que na empresa geradora destes, tendo a intenção de vendê-los, sejam contabilizados em conta específica no ativo circulante como instrumento financeiro disponível para a venda. $\mathrm{Na}$ Figura 1, os autores supracitados, desenvolveram em seus estudos, um esquema que esboça um tratamento contábil que poderia ser aplicado na geração dos créditos de carbono. 
Figura 1 - Tratamento contábil da geração de créditos de carbono

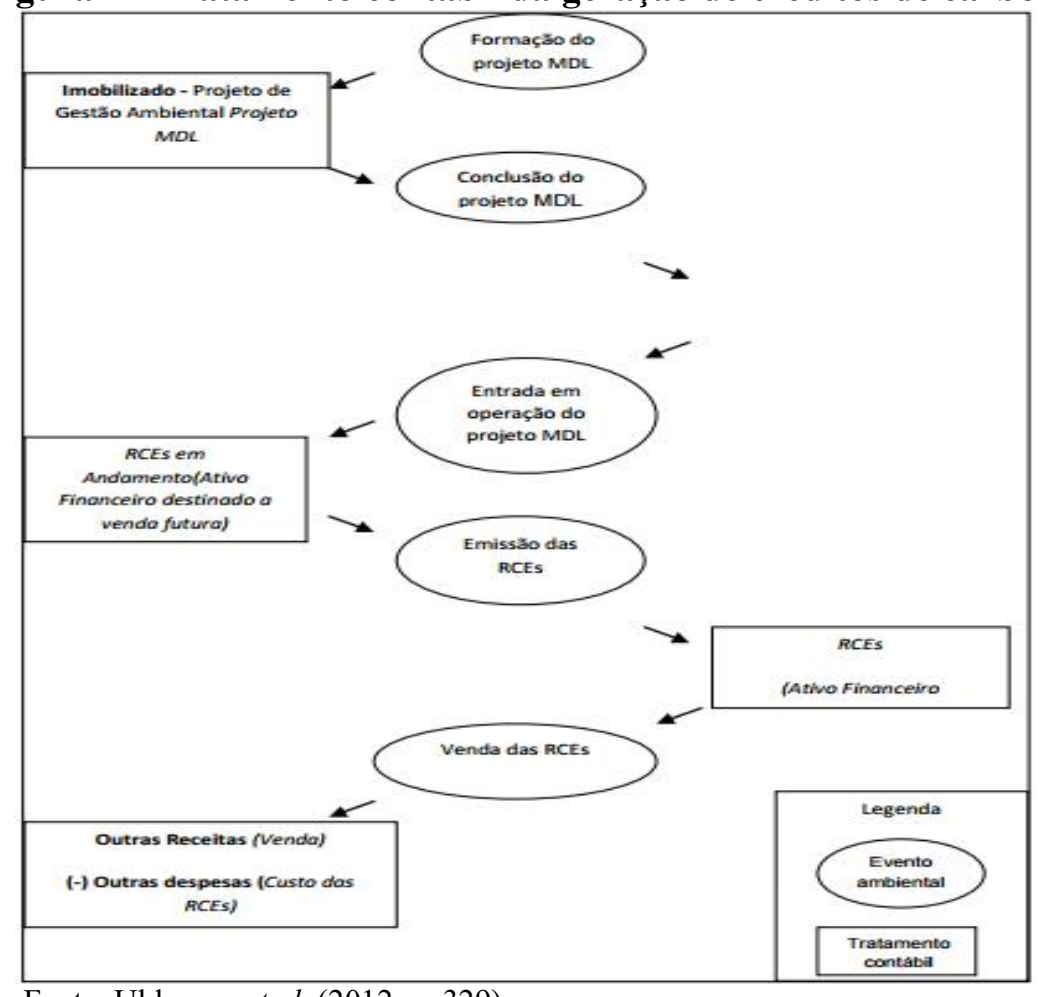

Fonte: Uhlmann et al. (2012, p. 329).

Com isso, para os autores, nas empresas adquirentes de tais RCEs, países desenvolvidos, os créditos de carbono constituem genuínos intangíveis, visto que são ativos incorpóreos, mensuráveis e utilizados nas atividades da empresa, ou seja, empresa adquirente comprará o direito de poluir por determinado período.

\section{METODOLOGIA}

A metodologia é "o método concretiza-se como o conjunto das diversas etapas ou passos que devem ser seguidos para a realização da pesquisa e que configuram as técnicas" (CERVO; BERVIAN; SILVA, 2007, p. 30). Assim, o presente estudo que tem como objetivo analisar como a participação da empresa em projetos de MDL e a venda de créditos de carbono auxiliam na situação econômico-financeira da organização, classifica-se como qualitativa, pois visa investigar e analisar a realidade como forma de coletar dados e entender o ambiente pesquisado quanto ao projeto de MDL e geração dos créditos de carbono, uma vez que, segundo Minayo (2009) a pesquisa qualitativa preocupa-se com aspectos da realidade que não podem ser quantificados, centrando-se na compreensão e explicação da dinâmica das relações do fenômeno observado, enquanto a pesquisa quantitativa centra-se na objetividade e quantificação dos dados pesquisados. Ademais, utilizou-se das técnicas de observação e descrição, procurando entender o ambiente onde ocorre a geração dos créditos de carbono, e a influência econômico-financeira que os mesmos exercem nas demonstrações contábeis da empresa.

Em relação aos procedimentos técnicos, classifica-se como uma pesquisa documental, uma vez que tornou-se necessário coletar informações junto aos demonstrativos financeiros: Balanço Patrimonial, Demonstração do Resultado do Exercício, Notas Explicativas, Relatório da Administração e Relatório de Sustentabilidade da empresa pesquisada e também, por Revista Ambiente Contábil - ISSN 2176-9036 - UFRN - Natal-RN. v. 9. n. 2, p. 296 - 314, jul./dez. 2017. 
buscar informações referentes aos projetos de MDL da Estação de Tratamento de Efluentes e da Usina de Co-geração.

Com isso, a análise e tratamento dos dados ocorreu mediante os cálculos dos índices para que se possa entender o comportamento da situação econômico-financeira da empresa, uma vez que esta, por ser uma companhia de capital aberto facilitou a coleta dos dados, pois seus relatórios encontram-se disponíveis no site da BM\&FBOVESPA. No entanto, para este estudo, analisou-se a evolução da situação econômico-financeira da referida empresa no período de 1997 a 2011, por meio da aplicação dos índices econômico-financeiros, nos quais, os dados foram extraídos das demonstrações financeiras foram tratados no Microsoft Office Excel $^{\circledR}$. No que tange a análise quanto a influência da participação em projetos MDL e geração de créditos de carbono por parte da empresa pesquisada, utilizou-se os seguintes demonstrativos: Relatórios de Sustentabilidade, Notas Explicativas e Relatórios da Administração de todo o período estudado, os quais foram obtidos da BM\&FBOVESPA.

\section{RESULTADOS E DISCUSSÕES}

Neste capítulo será apresentada a caracterização da empresa estudada, assim como seus procedimentos operacionais responsáveis pelos projetos de MDL e geração de créditos de carbono, além da análise econômico-financeira por meio dos índices econômicofinanceiros aplicados na empresa no período de 1997 a 2011 . A escolha do período de análise deu-se mediante a consistência das informações disponibilizadas pela empresa no site BM\&FBovespa, proporcionando uma melhor análise dos dados.

\subsection{CARACTERIZAÇÃO DA EMPRESA E SEUS PROJETOS DE MDL}

A empresa participante deste estudo, possui, atualmente, mais de 70 anos de atuação no mercado de celulose, uma vez que sua principal atividade é a produção de papel e celulose, assegurando o fornecimento de produtos de matéria-prima renovável com alta qualidade, sempre pensando no desenvolvimento sustentável, com o equilíbrio do meio ambiente e a sociedade, o que pode ser verificado por meio de seus projetos de MDL responsáveis pela geração dos créditos de carbono.

As matérias-primas utilizadas para a produção de papel são derivadas de duas fontes: materiais a serem reciclados e celulose natural que é retirada das áreas de reflorestamento. Desta forma, constatou-se que a organização produz papel e celulose utilizando-se do reflorestamento como prática da produção auto-sustentável de madeira para a extração da celulose colaborando com o equilíbrio ambiental. Deste processo produtivo surgem resíduos como águas residuais, detritos de base florestal (restos de madeira) e outros que prejudicam o meio ambiente, caso sejam descartados de forma incorreta. Com isso, no intuito de evitar e controlar a emissão de poluentes e o depósito irregular de resíduos perigosos a empresa desenvolveu dois projetos de MDL que evitam o descarte irregular desses resíduos e reduzem a emissão de gases de efeito estufa, aliando desenvolvimento e auto-sustentação.

Em se tratando dos projetos de MDL desenvolvidos pela empresa, está a Usina de Cogeração aprovada no ano de 2006, gerando créditos de carbono por meio da queima da biomassa (resíduos de madeira do processo produtivo), além de energia limpa, reduzindo a zero o impacto ambiental que seria causado pela decomposição da biomassa no meio ambiente, uma vez que geraria gases de efeito estufa, lembrando que as cinzas do processo produtivo são utilizadas como fertilizante nas áreas de reflorestamento.

Outro projeto de MDL desenvolvido é o referente à Estação de Tratamento de Efluentes aprovado em 2008, diz respeito ao tratamento das águas residuais utilizadas na produção do papel e da celulose, a qual passa por um processo aeróbio, evitando que o lodo

Revista Ambiente Contábil - ISSN 2176-9036 - UFRN - Natal-RN. v. 9. n. 2, p. 296 - 314, jul./dez. 2017. 
fique depositado no fundo das lagoas e gere o gás metano. O benefício deste processo, advém do efluente tratado, o qual pode ser direcionado para um rio sem material orgânico prejudicial ao mesmo e após o tratamento das águas residuais, o lodo ativado, neste caso, pode ser utilizado como fertilizante, ou depositado em aterros incinerados. Os dois projetos geram créditos de carbono, e são comercializados pela empresa produtora.

\subsection{ANÁLISE ECONÔMICO-FINANCEIRA POR MEIO DA UTILIZAÇÃO DE ÍNDICES}

As finanças de uma empresa podem afetar a estrutura da organização, uma vez que, a administração financeira deve ajudar a planejar o futuro da empresa e para que se possa acompanhar a evolução e identificar possíveis deficiências na gestão dos negócios, é de suma importância a análise das demonstrações financeiras por meio da utilização dos índices de estrutura de capitais e liquidez, que fazem parte da situação financeira. Já, a análise da situação econômica é uma avaliação da rentabilidade e lucratividade do desempenho da empresa, tendo como objetivo demonstrar por meio dos índices como a empresa vem utilizando o recurso investido.

Dessa forma, mediante os investimentos feitos pela empresa participante deste estudo em projetos MDL, tornou-se possível a análise da situação financeira pela utilização dos dados obtidos no Balanço Patrimonial que possibilitou o conhecimento do grau de endividamento da empresa no período pesquisado, assim como, a capacidade da mesma em cumprir com seus compromissos de curto e de longo prazo.

Assim sendo, a análise da situação econômica da companhia foi realizada por meio da aplicação dos índices de rentabilidade, feitos com base nos dados da Demonstração do Resultado do Exercício, que demonstraram o resultado alcançado pelo capital investido no negócio, e a comercialização dos créditos de carbono.

No que tange a participação de capitais de terceiros, no Gráfico 1 percebe-se o quanto a empresa utilizou de capitais de terceiros na implementação dos projetos MDL.

Gráfico 1: Participação de capitais de terceiros

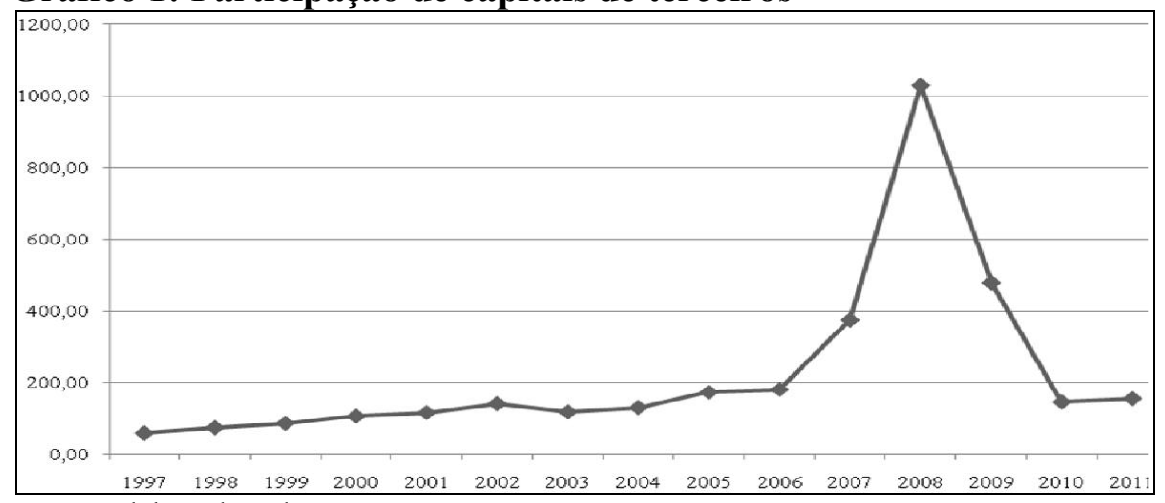

Fonte: Elaborado pelos autores.

No Gráfico 1, percebe-se a evolução do índice participação de capitais de terceiros durante o período de 1997 a 2011, no qual é possível observar que os anos com índices mais elevados estão entre 2005 a 2009 , demonstrando que a empresa possuía mais capitais de terceiros do que próprios. Neste período, a empresa investiu na implementação de seus projetos de MDL, como o da Usina de Co-geração em 2006 e o da Estação de Tratamento de Efluentes em 2008, tendo investimentos, segundo o Relatório de Sustentabilidade de 2006, de aproximadamente R $\$ 23.630,00$ de recursos. Dentro deste período, em 2007, a empresa

Revista Ambiente Contábil - ISSN 2176-9036 - UFRN - Natal-RN. v. 9. n. 2, p. 296 - 314, jul./dez. 2017. 
buscou recursos no valor de $\mathrm{R} \$ 8.143$ milhões também para a implementação dos projetos de MDLs, segundo o relatório de Notas Explicativas exposto pela empresa em análise.

Conforme informações construídas a partir dos Relatórios da Administração e Relatórios de Sustentabilidade, em tecnologias limpas e projetos que beneficiam o meioambiente a empresa utilizou de recursos em 2006 o montante de $\mathrm{R} \$ 8.6$ milhões, tendo seus primeiros créditos de carbono emitidos, fazendo com que a companhia fosse a primeira empresa brasileira do setor de papel e celulose e segunda no mundo a ter créditos de carbono emitidos pelo Protocolo de Quioto. Nos anos de 2007 e 2008, a empresa continuou utilizando recursos no aperfeiçoamento das tecnologias limpas, que foram de R \$ 3.8 milhões e R 3.3 milhões, respectivamente. Para o ano de 2011, tais recursos baixaram para R $\$ 7.899,00$, no mesmo ano o índice ficou em $154,55 \%$.

Além disso, a empresa realizou empréstimos com grandes bancos, somando um montante de R \$ 150.124 milhões, o qual o ano de 2008 teve o maior grau de endividamento $\mathrm{R} \$ 1.028,37$ de capital de terceiros para cada $\mathrm{R} \$ 100,00$ de capital próprio, ano em que a empresa mais utilizou recursos de terceiros para financiar seus ativos. A elevação do indicador neste ano está associada ao Mecanismo de Desenvolvimento Limpo (MDL) da Estação de Tratamento de Efluentes, que foi aprovado pela ONU em 2008 e a ampliação da capacidade de produção das unidades fabris de papelão ondulado a qual diz respeito ao Projeto Superação, sendo utilizado, neste projeto, recursos de R\$160.8 milhões. A partir de 2009 o índice voltou a diminuir, uma vez que começou a ocorrer a captura dos benefícios do Projeto Superação e a liquidação da dívida.

Apesar de o índice estar elevado no período analisado, deve-se considerar que os capitais de terceiros sempre existirão, tanto na forma de empréstimos, como financiamento da atividade normal, ou então, financiamentos para inovações tecnológicas que possibilitem um processo operacional sustentável, como é no caso da empresa pesquisada. Logo, o que importa é que a empresa saiba administrar bem tais recursos, fazendo com que os lucros obtidos na aplicação dos capitais de terceiros superem os custos desse capital.

No que tange a imobilização do patrimônio líquido, é possível averiguar qual a parcela do patrimônio líquido empregada para financiar o ativo não-circulante (diminuído do ativo realizável a longo prazo). O Gráfico 2, apresenta-se o estudo da evolução do índice de imobilização do patrimônio líquido.

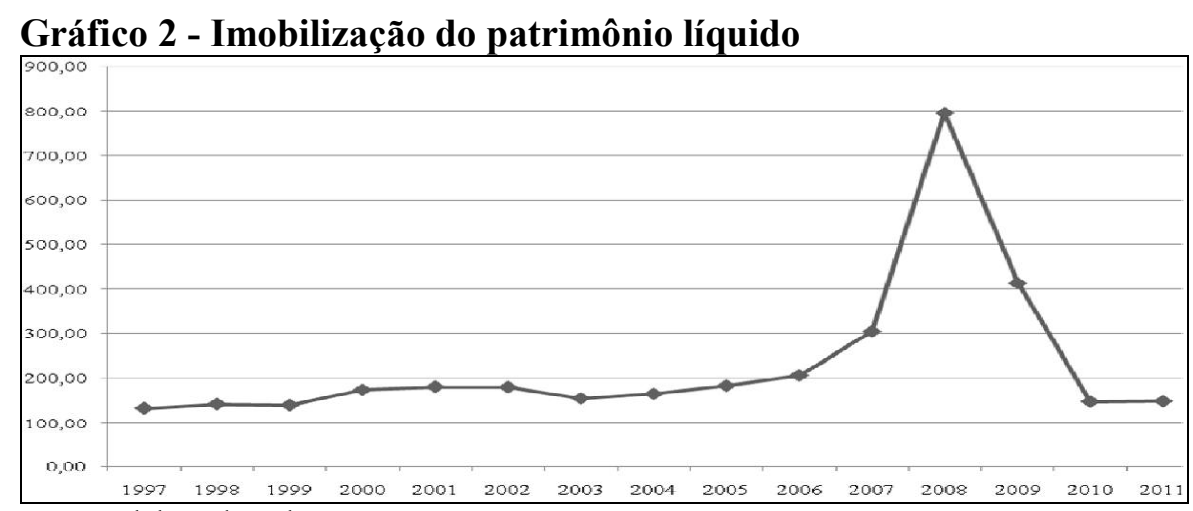

Fonte: Elaborado pelos autores.

Conforme o Gráfico 2 conjuntamente com informações observadas na empresa, percebe-se que foram investidos em tecnologias limpas e projetos que beneficiam o meio ambiente, dentre eles os projetos no âmbito do MDL, que no ano de 2006, quando o índice começou a elevar-se, teve uma soma registrado em Relatório de Sustentabilidade R 8.6 milhões. Assim, cabe salientar que o valor dos investimentos em um projeto de MDL varia de 
acordo com as tecnologias empregadas, aquisições de maquinários e abertura de novas fábricas.

No entanto, percebeu-se, mediante investigações na empresa em foco que o ano de 2008 teve o maior índice de imobilização do patrimônio líquido, uma vez que a conta com maior variação positiva de 2007 para 2008 foi a dos equipamentos e instalações com R\$ 106.782 milhões. Destarte, diante do exposto é possível mencionar que os investimentos em tecnologias limpas e projetos que beneficiam o meio ambiente, em 2008, somaram um total de R 3.3 milhões, e que no ano citado em que o índice permaneceu elevado, foram investidas grandes quantias no Projeto Superação.

Portanto, durante o período que o índice se apresenta mais elevado, acima de 100\%, indica que a empresa aplicou em seu ativo não circulante (menos o realizável a longo prazo), todo o seu capital próprio e ainda uma parcela de capitais de terceiros.

Ao analisar o índice pela Liquidez imediata, este revelou se a empresa possuía, no período analisado, disponibilidades suficientes para saldar seus compromissos de curto prazo, indicando quanto a empresa tinha de dinheiro em caixa, nos bancos e em aplicações de liquidez imediata, para cada $\mathrm{R} \$ 1,00$ do passivo circulante. No Gráfico 3 encontra-se o estudo da evolução do índice, no período de 1997 a 2011.

\section{Gráfico 3: Liquidez imediata}

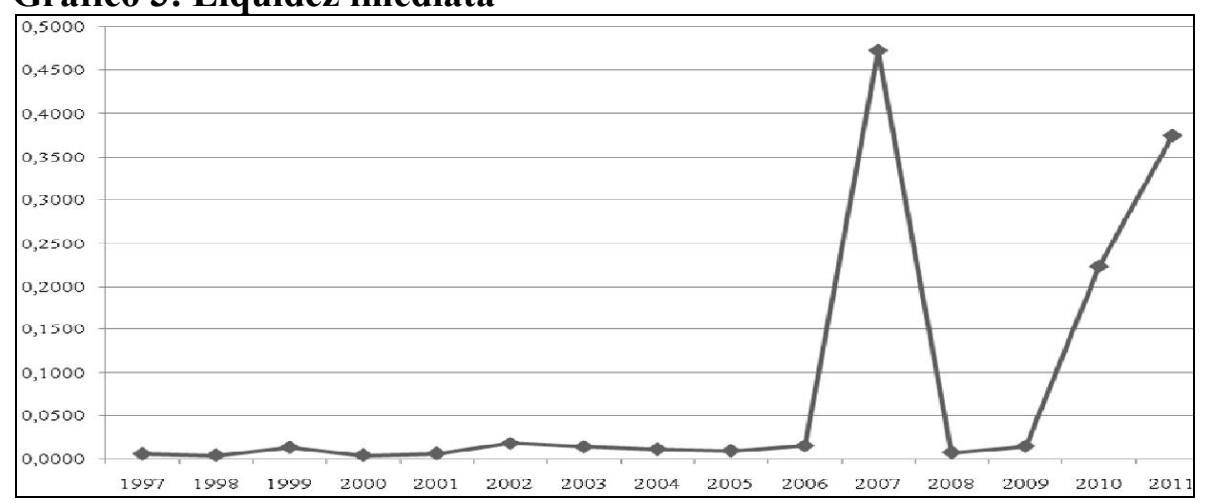

Fonte: Elaborado pelos autores.

No primeiro ano analisado 1997, constata-se que a empresa possuía $\mathrm{R} \$ 0,0055$ de disponibilidades para cada $\mathrm{R} \$ 1,00$ de obrigações a curto prazo, este foi o ano com menor índice, apesar de todo o período apresentar-se abaixo de um. $\mathrm{O}$ ano que obteve a maior liquidez imediata foi o de 2007, a qual chegou à $\mathrm{R} \$ 0,4720$ de caixa, bancos e aplicações de liquidez imediata para cada $\mathrm{R} \$ 1,00$ do passivo circulante. No ano de 2007, em que o índice atingiu o auge do período, a receita da empresa deu-se mediante a comercialização dos créditos de carbono, no valor de R $\$ 1.85$ milhões.

A permanência dos índices, desde 1997 até 2011, abaixo de um, não se configura situação de insolvência, uma vez que, a companhia pode ter prazos de vencimento de suas obrigações a curto prazo suficientes para permitir a empresa obter recursos a fim de pagá-los com o desenvolvimento normal de suas atividades e com isso, não precisa manter grande volume de caixa.

Outro índice analisado foi quanto a Liquidez corrente, uma vez que esta apresentou a capacidade financeira da empresa em cumprir os seus compromissos de curto prazo no período analisado, isto é, quanto a empresa teve de ativo circulante em cada ano para cada $\mathrm{R} \$$ 1,00 de passivo circulante, conforme o Gráfico 4. 
Gráfico 4: Liquidez corrente

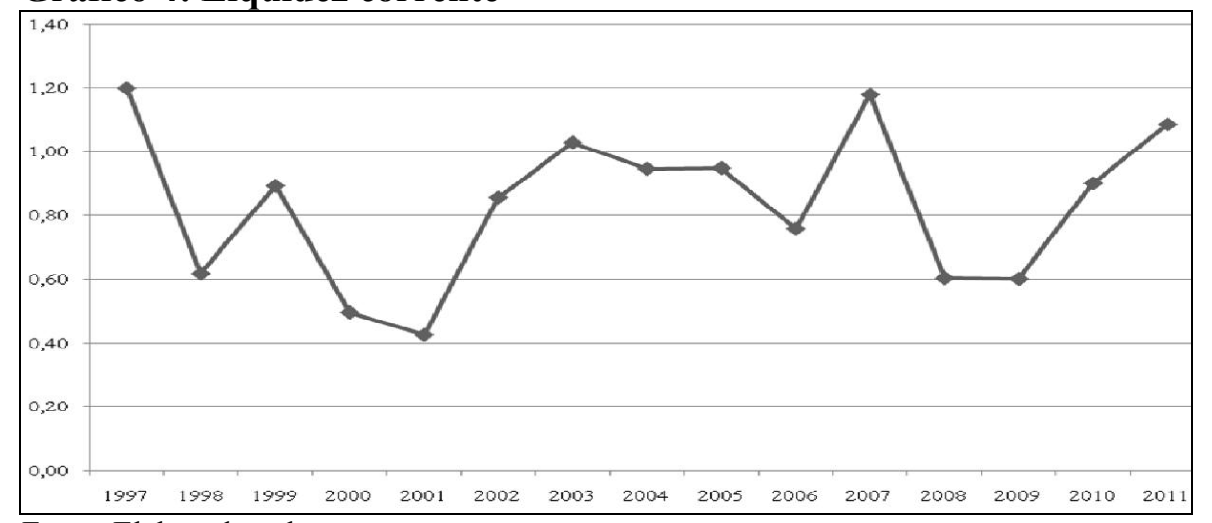

Fonte: Elaborado pelos autores.

Como pode-se verificar com a análise do Gráfico 4, o ano de 1997 teve o maior índice de liquidez corrente, uma vez que a empresa possuía $\mathrm{R} \$ 1,20$ de ativo circulante para cada $\mathrm{R} \$$ 1,00 de passivo circulante. Portanto, nesse ano os recursos eram suficientes para pagar todas as obrigações de curto prazo e ainda sobrar uma folga financeira de $\mathrm{R} \$ 0,20$ para cada $\mathrm{R} \$$ 1,00 de dívida. O ano de 2001 ficou com o menor índice de todo o período, chegando a $\mathrm{R} \$$ 0,43. Em 2007 o índice melhorou, ficando com $\mathrm{R} \$ 1,18$ de direitos de curto prazo para cada $\mathrm{R} \$ 1,00$ de passivo circulante, considerando que a receita operacional líquida foi $16,6 \%$ superior, no ano de 2007, em relação a 2006. Ainda no ano de 2007, a empresa realizou a venda de créditos de carbono que somaram um montante de R\$1.85 milhões, conforme o Relatório da Administração, uma vez que, nos anos em que a liquidez corrente foi maior que 1,00 a organização não teve dificuldades em efetuar suas transações, demonstrando melhor adequação do vencimento da dívida de curto prazo à capacidade de pagamento da companhia.

No que tange a Margem líquida ou lucratividade, pretendeu-se, ao analisar este índice verificar quanto a empresa obteve de lucro líquido para cada $\mathrm{R} \$ 100,00$ vendidos, ou seja, qual a margem de lucro da empresa em função do seu faturamento. O Gráfico 5 apresenta o estudo da evolução do índice durante os anos de 1997 a 2011.

Gráfico 5: Margem líquida

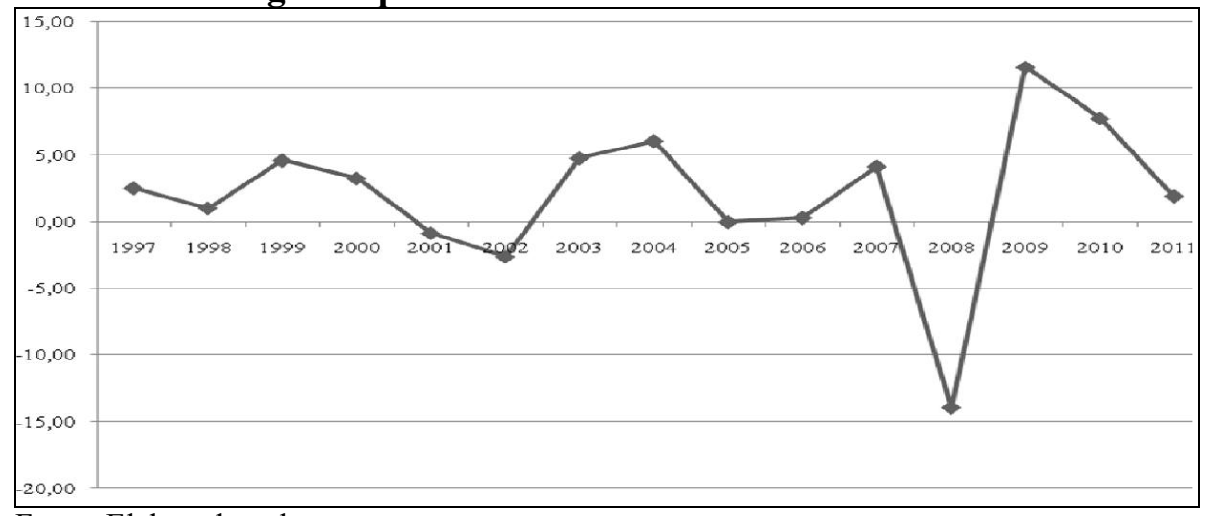

Fonte: Elaborado pelos autores.

Analisando o período, este começou com R $\$ 2,55$ de lucro para cada R $\$ 100,00$ vendidos no ano de 1997, tendo um pequeno aumento em 1999 de R \$4,60, porém em 2002 a margem de lucro baixou ficando com R \$ 2,63 negativos. Entre os anos de 2002 a 2007 ocorreram oscilações no índice e em 2007 percebe-se uma elevação na margem líquida de R\$

Revista Ambiente Contábil - ISSN 2176-9036 - UFRN - Natal-RN. v. 9. n. 2, p. 296 - 314, jul./dez. 2017. 
4,17 de lucro líquido para cada R\$ 100,00 vendidos, já que os lucros aumentaram de 2006 para 2007, juntamente com as vendas líquidas. Neste ano, segundo as Notas Explicativas de 2007, a companhia efetuou venda de créditos de carbono de $\mathrm{R} \$ 1.851$ milhões (R $\$ 3.057$ milhões em 2006), registrado como "Outras receitas operacionais"

Assim, percebe-se que no ano de 2008, a margem líquida foi a menor de todo o período, ou seja, $\mathrm{R} \$ 13,96$ negativos para cada $\mathrm{R} \$ 100,00$ de faturamento, isso ocorreu devido aos investimentos no Projeto Superação, o qual foi explicado nos índices anteriores. Convém salientar que, houve considerável aumento na margem líquida em 2009, a maior de todos os anos estudados, ou seja, $\mathrm{R} \$ 11,57$ de lucro líquido para cada $\mathrm{R} \$ 100,00$ de vendas. Com isso, pode-se averiguar que a relação da margem liquida se deu pelo fato de que neste ano a comercialização dos créditos de carbono somou um montante de R $\$ 4.314$ milhões, de acordo com o Relatório de Sustentabilidade e o lucro líquido teve um aumento significativa, apesar das vendas registrarem uma pequena diminuição.

Acerca da Rentabilidade do ativo, o qual demonstra o potencial de geração de lucros por parte da empresa, ou seja, quanto a mesma obteve de lucro líquido para cada $\mathrm{R} \$ 100,00$ de investimentos totais, está representado no Gráfico 6, por meio do estudo da evolução da rentabilidade do ativo durante o período de 1997 a 2011.

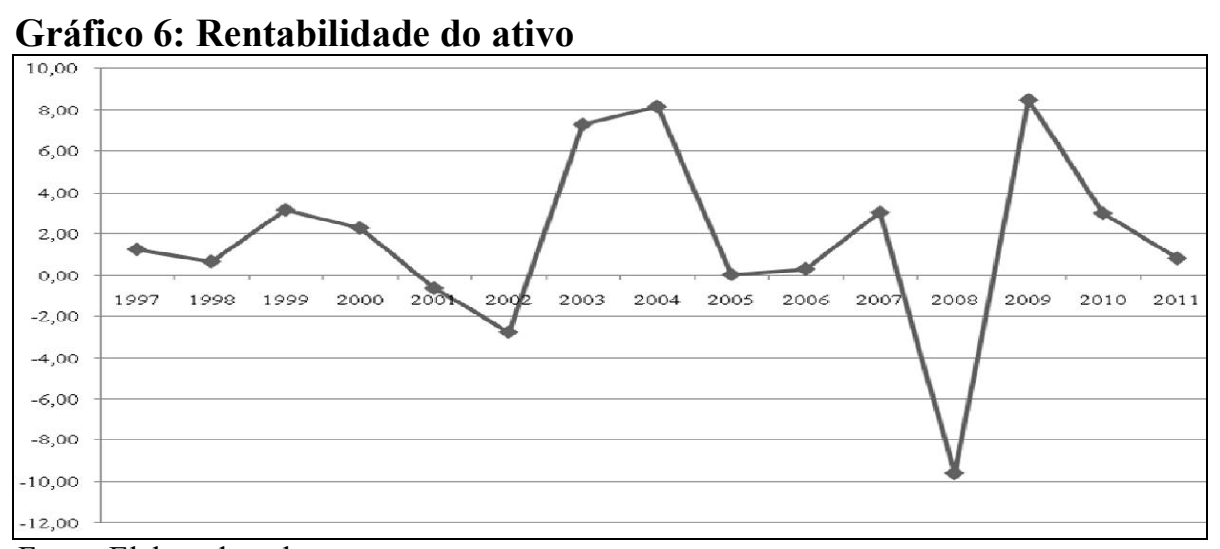

Fonte: Elaborado pelos autores.

O índice do período em 1997 inicia com $\mathrm{R} \$ 1,23$ de lucro para cada $\mathrm{R} \$ 100,00$ de investimento total e quanto maior for este índice, melhor será para a companhia. Porém, percebe-se que em 2008 o índice atingiu o pior desempenho de todo o período, ou seja, R\$ 9,62 negativos. O baixo desempenho neste ano é resultante do prejuízo obtido pela empresa e aumento dos ativos totais de 2007 para 2008. No ano de 2009 voltou a elevar-se chegando a $\mathrm{R} \$ 11,57$ de lucro líquido para cada $\mathrm{R} \$ 100,00$ de investimentos totais, ano em que a companhia obteve o melhor desempenho devido ao aumento do lucro líquido e diminuição dos ativos totais de 2008 para 2009.

Ainda, percebe-se que a empresa obteve o valor de R \$ 3.057 milhões em 2006 com a venda de créditos de carbono, segundo o Relatório de Sustentabilidade, enquanto no ano de 2007, essa venda foi de R\$ 1.8 milhão. Por sua vez, no ano de 2008, a venda dos créditos atingiu o valor de $\mathrm{R} \$ 5.1$ milhões. No ano em que o índice apresentou o melhor desempenho, foi em 2009, no qual a receita com a venda de créditos de carbono foi de R $\$ 4.314$ milhões, sendo que, neste ano, a organização começou a se beneficiar dos investimentos efetuados pelo Projeto Superação, conforme o Relatório da Sustentabilidade.

Outro índice analisado foi quanto ao da rentabilidade do patrimônio líquido, uma vez que por meio da análise deste índice foi possível verificar quanto a organização obteve de lucro para cada $\mathrm{R} \$ 100,00$ de capital próprio investido, conforme Gráfico 7. 


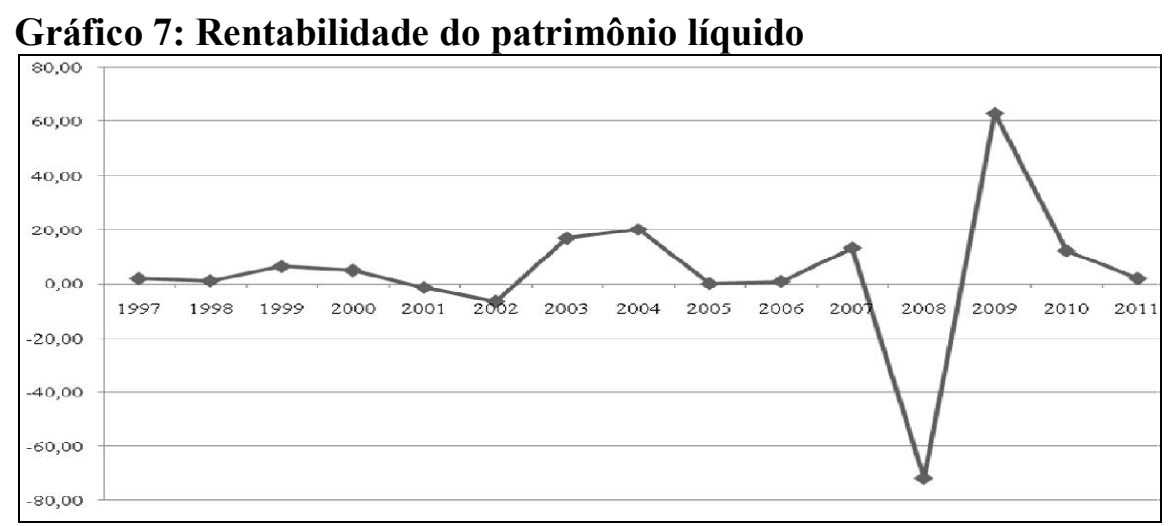

Fonte: Elaborado pelos autores.

Com isso, verifica-se que de todo o período analisado, o ano de 2008 teve a menor rentabilidade do patrimônio líquido atingindo $\mathrm{R} \$ 71,88$ negativos para cada $\mathrm{R} \$ 100,00$ de capital próprio investido, neste ano a situação agravou-se devido ao prejuízo no ano de 2008 e o aumento no saldo do patrimônio líquido de 2007 para 2008. Por outro lado, o ano seguinte (2009) atingiu um valor positivo de R \$ 62,39 ficando com o melhor índice de todos os anos estudados, uma vez que tanto o lucro líquido, quanto o patrimônio líquido tiveram aumento expressivo.

Ademais, a empresa obteve uma receita extra de cerca de $\mathrm{R} \$ 9$ milhões com a venda de créditos de carbono no período estudado. Em 2008 foram contabilizadas receitas líquidas com a venda de créditos de carbono de $\mathrm{R} \$ 5.1$ milhões referente a dois projetos de MDL aprovados na ONU. Em 2009 R 3.2 milhões foram aprovados para a empresa, sendo que este foi o ano da consolidação dos investimentos feitos em 2007 e 2008 e do início da captura dos seus benefícios, segundo o Relatório da Sustentabilidade.

\section{CONCLUSÕES}

Diante do exposto, o presente estudo buscou analisar como a participação da empresa em projetos de MDL e geração de créditos de carbono auxiliam na situação econômicofinanceira da organização, uma vez que, para conhecer melhor a situação econômicofinanceira de uma empresa que se preocupa e investe na preservação do meio ambiente, podese fazer a aplicação de índices que são indispensáveis ao processo de avaliação patrimonial e do desempenho da empresa.

Percebeu-se, com isso, que com o advento de uma nova possibilidade de desenvolverse sem deixar de lado a preocupação com os recursos naturais e a busca pela sustentabilidade, é que as companhias brasileiras passaram a interessar-se pela utilização adequada e descarte controlado de seus resíduos produtivos.

Para tanto, analisou-se a situação econômico-financeira da companhia em foco, por um período de 15 anos, por meio da aplicação dos índices econômico-financeiros em uma empresa que possui projetos de MDL e geração dos créditos de carbono, durante o período em que a organização teve maior produção destes. Para isso, utilizou-se as demonstrações financeiras, mais especificamente o Balanço Patrimonial e a Demonstração do Resultado do Exercício no período de 1997 até 2011, disponibilizadas no site da BM\&FBovespa.

Com a aplicação dos índices de estrutura de capitais e os de liquidez, pela estrutura de capitais percebe-se o nível de dependência de capital de terceiros da empresa enfrentou durante o período anterior e posterior à geração dos créditos de carbono. De acordo com os dados analisados, os índices de liquidez mostraram que os ativos da empresa foram

Revista Ambiente Contábil - ISSN 2176-9036 - UFRN - Natal-RN. v. 9. n. 2, p. 296 - 314, jul./dez. 2017. 
suficientes para o pagamento de suas dívidas, estando nestes, inseridos os investimentos realizados a partir da construção e implantação dos projetos de MDL desenvolvidos pela companhia e os investimentos responsáveis pelo aumento da capacidade produtiva da indústria de papel e celulose referente ao Projeto Superação.

No entanto, vale ressaltar que a utilização de recursos de terceiros não é prejudicial à empresa, desde que ela saiba administrar tais recursos, sendo que isso ocorre com a empresa estudada, uma vez que já no ano de 2009 os índices passaram a melhorar, pois a companhia começava a capturar os benefícios advindos dos investimentos efetuados para melhora da capacidade produtiva. E antes disso, já se utilizava das receitas auferidas com a venda dos créditos de carbono que somaram valores consideráveis de recursos para a organização.

Quanto à situação financeira averiguou-se que houve relevante utilização de recursos de terceiros e o aumento de suas imobilizações no período de 2006 a 2008 devido aos investimentos nos Mecanismos de Desenvolvimento Limpo (MDL) o da Usina de Co-geração em 2006 e da Estação de Tratamento de Efluentes, que foi aprovado pela ONU em 2008 e a ampliação da capacidade de produção das unidades fabris que consumiram grande quantidade de recursos. Situação que também influenciou a liquidez, visto que neste período a empresa utilizou-se de seus recursos para saldar as dívidas referentes aos projetos de MDL e ao aumento da capacidade produtiva.

No que tange a evolução dos índices para análise da influência dos créditos de carbono na situação econômico-financeira da empresa, a mesma foi viável devido à elaboração dos gráficos que mostram o comportamento dos índices desde 1997 até 2011. Portanto, constatouse que os investimentos em projetos de MDL trouxeram receita extra e redução do impacto ambiental do processo produtivo da empresa em foco, por meio da criação de tecnologias limpas que diversificaram sua matriz energética, diminuindo os gastos com energia elétrica, uma vantagem estratégica, visto que, os consumidores valorizam cada vez mais empresas sustentáveis que investem na redução do impacto ambiental de suas atividades, melhorando a imagem de seus produtos frente à sociedade.

Percebe-se também que, em se tratando dos projetos de MDL para a geração de créditos de carbono, ao que parece, estes influenciam positivamente a situação econômicofinanceira da empresa, visto que a receita extra dos créditos de carbono contabilizada pela empresa como "Outras receitas operacionais" advém da soma de um montante de milhões de reais e, se não fosse considerado o ingresso desse recurso, provavelmente os índices apresentariam um desempenho menor.

Por fim, percebe-se, mediante a emissão dos créditos de carbono, que a empresa possuidora dos certificados, poderá vendê-los, buscando assim, um maior retorno sobre seus investimentos bem como, um diferencial em relação a seus concorrentes. Diante deste contexto, surge a necessidade de procedimentos voltados para o planejamento e controle das questões ambientais, bem como o atendimento legal quanto à comercialização destes.

Como limitação à pesquisa, tem-se o fato da mesma tratar de um tema incipiente, havendo espaço para outras análises que levem a conclusões diferentes das apresentadas neste estudo, até mesmo se os pesquisadores tivessem acesso a outras informações, os resultados também, poderiam ser diferentes. Assim, recomenda-se que outras pesquisas sejam desenvolvidas sobre os resultados que os investimentos em processos produtivos sustentáveis, diferentes dos apresentados aqui, podem trazer às empresas de diversos setores de atuação, ligando-os a eventos relacionados à contabilidade e ao meio ambiente.

\section{REFERÊNCIAS}

ALVES-MAZZOTTI, A. J. Usos e abusos dos estudos de caso. Cadernos de Pesquisa (online) - São Luís 36 (129): 637-651, set./dez. 2006.

Revista Ambiente Contábil - ISSN 2176-9036 - UFRN - Natal-RN. v. 9. n. 2, p. 296 - 314, jul./dez. 2017. 
BARBIERI, K. S.; RIBEIRO, M. S. Mercado de créditos de carbono: aspectos comerciais e contábeis. In: Congresso USP de Controladoria e Contabilidade, 7, 2007, São Paulo. Anais... São Paulo: USP, 2007. Disponível $<$ http://www.congressousp.fipecafi.org/artigos72007/68.pdf $>$. Acesso em: 21 abr. 2012.

BEN, F.; TONELLO, K. A. Análise do reconhecimento contábil dos créditos de carbono. In: XI Convenção de Contabilidade do Rio Grande do Sul. Anais... Bento Gonçalves, Rio Grande do Sul, 2007.

BM\&FBOVESPA. Demonstrativos Financeiros da Celulose Irani S.A.. Disponível em: $<$ http://www.bmfbovespa.com.br/cias-listadas/empresas-

listadas/HistoricoFormularioReferencia.aspx? codigoCVM=2429\&tipo $=\mathrm{dfp} \& a n o=0 \&$ idioma $=$ pt-br>. Acesso em: 10 out. 2012.

BM\&FBOVESPA. Mercado de Carbono: Perguntas frequentes, 2016. Disponível em: $<$ www.bmfbovespa.com.br/pt-br/mercados/mercado-de-carbono/mercadodecarbono.aspx?aba=tabItem4\&= \&idioma=pt-br>. Acesso em: 25 fev. 2016.

BRASIL. Ministério da Ciência e Tecnologia. Protocolo de Quioto. Editado e traduzido pelo Ministério da Ciência e Tecnologia com o apoio do Ministério das Relações Exteriores da República Federativa do Brasil. 2012. Disponível em: $<$ http://mudancasclimaticas.cptec.inpe.br/ rmclima/pdfs/Protocolo_Quioto.pdf $>$. Acesso em: 05 ago. 2011.

CEBDS - Conselho Empresarial Brasileiro para o Desenvolvimento Sustentável. Mecanismo de Desenvolvimento Limpo, 2009. Disponível em: <http://www.cebds.org.br/cebds/pubdocs/pub-mc-mdl.pdf>. Acesso em: 20 jul. 2016.

CERVO, A. L.; BeRVIAN, P. A.; SILVA, R. Metodologia Científica. 6. ed. São Paulo: Pearson Prentice Hall, 2007.

COElhO, A. R. G.; LIBONATI, J. J.; LAGIOIA, U. C. T.; MACIEL, C. V. A comercialização e a contabilização dos créditos de carbono com base em projetos de mecanismo de desenvolvimento limpo. Pensar Contábil - Rio de Janeiro 10 (41): 44-52, 2008.

CRUZ, S. S; PAULINO, S. R. Local use of resources from clean development mechanism projects in landfill sites in the city of São Paulo. Revista Sociedade e Ambiente - São Paulo 16 (1): 117-140, jan./mar. 2013.

DELGADO, M. F.; ALTHEMAN, E. Estudo sobre a viabilidade financeira do Mercado de Carbono. UNOPAR Científica Ciências Jurídicas e Empresariais - Londrina 8 (1): 39-48, mar. 2007.

FREIRE, R. S.; CARMONA, C. U. M.; SALES, J. D. A.; ANJOS, L. C. M.; QUEIROGA, A. A.; OURO FILHO, A. M.; LUCIAN, R. Mecanismo de desenvolvimento limpo: um ensaio teórico sob a ótica da estratégia e dos custos de transação. Revista Ibero-Americana de Ciências Ambientais - Aracaju 6 (1). 2015. 
FRONDIZI, I. M. R. L. O Mecanismo de Desenvolvimento Limpo: Guia de Orientação 2009. Rio de Janeiro: Imperial Novo Milênio, 2009.

GAZONI, A. C. O Protocolo de Kyoto e o estabelecimento de metas de redução de GG. In: SOUZA, R. P. (Coord.). Aquecimento global e créditos de carbono. São Paulo: Quartier Latin, 2007. pp. 53-61.

GIOVANINI, D.A; CORSATO, A.C.; MONASSA, C.C.S. Análise do Mercado de Créditos de Carbono: Aplicação de projetos MDL no Brasil. In: V Encontro Nacional da Anppas, 2010, Florianópolis. Anais... Florianópolis: Anppas, 2010.

INSTITUTO BRASIL CARBONO. Financiamentos, 2012. Disponível em: $<$ http://www.institutocarbonobrasil.org.br/mecanismo_de_desenvolvimento_limpo_mdl_fin anciamentos>. Acesso em: 20 jun. 2012.

KHALILI, A. E. O que são créditos de carbono? Revista ECO 21, Rio de Janeiro, ano XII, v. 12, n. 74, jan 2003. Disponível em: <http://www.eco21.com.br/textos/textos.asp?ID=436>. Acesso em: 20 jun. 2012.

LIMIRO, D. Créditos de carbono: protocolo de Kyoto e projetos MDL. Curitiba: Juruá, 2011.

LOMBARDI, A. Créditos de Carbono e Sustentabilidade. São Paulo: Lazuli, 2008.

MINAYO, M. C. S. O desafio da pesquisa social. In: MINAYO, M. C. S. (Coord.). Pesquisa social: teoria, método e criatividade. 28. ed. Petrópolis: Vozes, 2009. pp. 09-29.

MINISTÉRIO DA CIÊNCIA E TECNOLOGIA. Convenção sobre mudança do clima. 2012. Disponível em: <http://www.mct.gov.br/upd_blob/0005/5390.pdf >. Acesso em: 20 jun. 2012.

RIBEIRO, M. S. O tratamento contábil dos créditos de carbono. 2005. 90 f. Tese (Doutorado de Livre Docência em Contabilidade Geral) - Faculdade de Economia, Administração e Contabilidade, Universidade de São Paulo, São Paulo, 2005.

ROBLES JÚNIOR, A.; BONELLI, V. V. Gestão de qualidade e do meio ambiente: enfoque econômico, financeiro e patrimonial. São Paulo: Atlas, 2006.

SEIFFERT, M. E. B. Mercado de carbono e protocolo de Quioto: oportunidade de negócio na busca da sustentabilidade. São Paulo: Atlas, 2009.

SILVA, L.F.; MACEDO, A.H. Um estudo exploratório sobre o crédito de carbono como forma de investimento. Revista Eletrônica em Gestão, Educação e Tecnologia Ambiental Santa Maria 8 (8): 1651-1669, set./dez. 2012.

TEIXEIRA, E. M. L. C.; SUZUKI, E.; VIEIRA, S.S; MORAES de, J. E.; LUCENA, M. A. C. de; OLIVEIRA, E. A.; CANOVA, E. B.; ARANTES, A. M.; CONCEIÇÃO, M. R. G.; OUTRAMARI, C. E.; ZOTTI, C. A.; PAULINO, V. T. Mercado de Crédito de Carbono. 2010. Infobibos Informações. Disponível em: 
$<$ http://www.infobibos.com/Artigos/2010_2/CreditoCarbono/index.htm>. Acesso em: 20 jun. 2012.

UHLMANN, V.O.; SOUZA, M.M.; PFITSCHER, E.D.; FREY, I.A. Tratamento contábil dos créditos de carbono: uma análise à luz das normas do comitê de pronunciamentos contábeis. Revista em Agronegócios e Meio Ambiente - Maringá 5 (2): 311-335, maio./ago. 2012.

VALDETARO, E. B., SILVA, F. L. D., RIBEIRO, S. C., JACOVINE, L. A. G. Contribuição dos créditos de carbono na viabilidade econômica dos contratos de fomento florestal no sul da Bahia. Revista Árvore - Viçosa-MG, 35 (6): 1307-1317, 2011. 